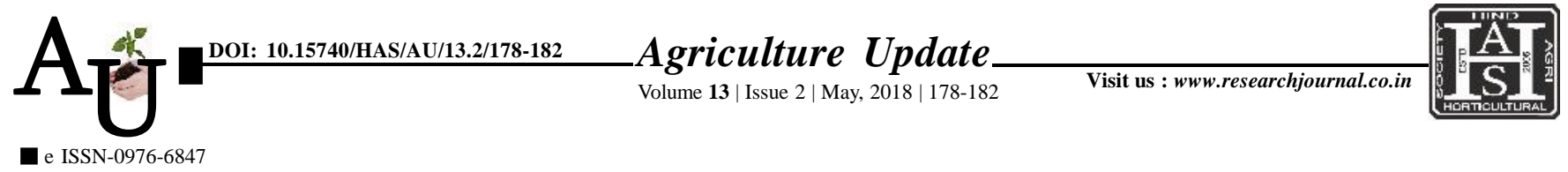

\title{
Research Article: A study on knowledge and adoption of integrated pest management (IPM) by rice growers
}

Article Chronicle:
Received :
29.01.2018;
Revised :
24.03.2018;
Accepted :
09.04.2018

KeY Words : Knowledge, Adoption, IPM practices, Rice growers

Author for correspondence :

Quadri Javeed Ahmed Peer

Division of Agriculture

Extension and

Communication, Faculty of Agriculture (SKUAST$\mathrm{K})$, Wadura (J\&K) India Email:qadrijavid2008@ gmail.com

See end of the article for authors' affiliations
SUMMARY : The study was conducted in Kadapa district of Rayalaseema region in Andhra Pradesh on the knowledge and adoption level of integrated pest management practices by rice growers. It was found that majority (64.00\%) of the respondents belonged to middle age and most of them (36.66\%) were illiterates. It was found that regarding land holding majority $(38.00 \%)$ of the respondents were semi-medium(5.01-10.00acres) farmers whereas (49.33\%) of respondents were cultivating paddy in an area upto 1 acre and majority (64.66\%) of the respondents were having medium level of farming experience. It was also found that majority $(64.66 \%)$ of the respondents belongs to general caste and $(55.33 \%)$ of the respondents were having medium level of annual income (2-5lakhs). Observations showed that $(53.33 \%),(56.00 \%)$ and $(54.00 \%)$ of the respondents had medium level of mass media participation, extension contacts and scientific orientation, respectively. More than half of the respondents had medium level of knowledge (59.33\%) and had medium level of adoption $(56.66 \%)$ of IPM practices of rice. Regarding few cultural practices respondents had (100.00\%) knowledge and adoption. For the IPM practice "Use of biopesticides like Pandora delphacis against BPH" farmers had no knowledge and no farmer adopted it.

How to cite this article : Sreekanth, Maddina, Peer, Quadri Javeed Ahmed, Chowdary, K. Ragavendra, Ganai, N.A., Bhat, B.A. and Farhana (2018). A study on knowledge and adoption of integrated pest management (IPM) by rice growers. Agric. Update, 13(2): 178-182; DOI : 10.15740/HAS/AU/13.2/178-182. Copyright@ 2018: Hind Agri-Horticultural Society. 